\title{
Biogeochemical Controls on Mercury Methylation in Arctic Tundra Soils
}

LiJIE ZHANG ${ }^{1}$, MichaEL PHILBEN ${ }^{1}$, ZIMING YANG ${ }^{2}$, ERIC M. PIERCE ${ }^{1}$, DAVID E. GRAHAM ${ }^{3}$, AND BAOHUA GU ${ }^{1,4}$

${ }^{1}$ Environmental Sciences Division, Oak Ridge National Laboratory, Oak Ridge, TN 37830, USA

${ }^{2}$ Department of Chemistry, Oakland University, Rochester, MI 48309, USA

${ }^{3}$ Bioscience Division, Oak Ridge National Laboratory, Oak Ridge, TN 37831, USA

${ }^{4}$ Department of Biosystems Engineering and Soil Science, University of Tennessee, Knoxville, TN 37996, USA

Arctic tundra soils store a globally significant amount of mercury $(\mathrm{Hg})$ as a result of long-distance transport and atmospheric deposition of $\mathrm{Hg}$ to the polar region. The greatest toxicological concern of $\mathrm{Hg}$ pollution is its transformation to methylmercury $(\mathrm{MeHg})$, a neurotoxin that can bioaccumulate and biomagnify in Arctic ecosystems. However, our current knowledge of biogeochemical transformation of inorganic $\mathrm{Hg}$ to $\mathrm{MeHg}$ in Arctic tundra is insufficient, especially regarding the geochemical and microbial factors controlling $\mathrm{MeHg}$ production. In this study, we investigated the effect of different substrates (acetate and sulfate) and selective microbial inhibitors (molybdate and 2-bromoethanesulfonate) on $\mathrm{Hg}$ methylation in two Arctic tundra soils - collected at the Teller and Council sites near Nome, Alaska USA-with differing geochemical characteristics (e.g., dissolved organic $\mathrm{C}$ and sulfate concentrations). Our results indicate that increasing acetate availability had negligible influence on $\mathrm{MeHg}$ production, suggesting that acetate was not a limiting factor on $\mathrm{Hg}$ methylation in both soils. Experiments conducted with the microbial inhibitors show that sulfatereducing bacteria are the major contributors to $\mathrm{MeHg}$ production in the first 15 days of incubation with the soils from Teller site. This $\mathrm{MeHg}$ production coincided with the depletion of sulfate, following which methanogens played a role in continued $\mathrm{MeHg}$ production. In contrast, methanogens and sulfate-reducing bacteria both contributed to the $\mathrm{MeHg}$ production in the Council soil throughout the incubation. Due to a low sulfate availability, addition of sulfate increased $\mathrm{MeHg}$ production by 6-fold in the Council soil, suggesting that $\mathrm{MeHg}$ production was stimulated by dissimilatory sulfate-reducing bacteria. Together our results indicate that sulfate-reducing bacteria and methanogens are the dominant methylators with their activities depend on geochemical factors, such as the availability of sulfate in these tundra soils. 